Article

\title{
Extraction and Spatial-Temporal Evolution of Urban Fringes: A Case Study of Changchun in Jilin Province, China
}

\author{
Shouzhi Chang ${ }^{1,2}{ }^{(1)}$, Qigang Jiang ${ }^{1, *}$, Zongming Wang ${ }^{3}$, Sujuan $\mathrm{Xu}^{4}$ and Mingming Jia ${ }^{3}$ (1) \\ 1 College of Geo-Exploration Science and Technology, Jilin University, Changchun 130026, China; \\ changshouzhi@126.com \\ 2 Changchun Institute of Urban Planning and Design, Changchun 130022, China \\ 3 Northeast Institute of Geography and Agroecology, Chinese Academy of Sciences, \\ Changchun 130102, China; zongmingwang@iga.ac.cn (Z.W.); jiamingming@iga.ac.cn (M.J.) \\ 4 Jilin Province Zhongshi Testing Company, Changchun 130000, China; xusujuan919@126.com \\ * Correspondence: jiangqigang@jlu.edu.cn; Tel.: +86-0431-8850-2426
}

Received: 12 May 2018; Accepted: 18 June 2018; Published: 22 June 2018

\begin{abstract}
An urban fringe area, depicted as a typical ecotone, is a region where both social and environmental problems are concentrated. Identifying and evaluating the spatial-temporal characteristics of urban fringe areas is significant for future development. On the basis of the land use data extracted from remote sensing data, the Shannon diversity index (SHDI) of each unit can be calculated, and identifying the urban fringe area by the breakpoint method is reliable. By using the rapidly growing Changchun as example, this study identifies the urban fringe of Changchun in 1995, 2005, and 2015 by applying the breakpoint method. The expansion amount, change mode, direction of expansion, landscape, and influence factors are evaluated. Policy and planning are the main factors influencing the development direction of the Changchun fringe area. The urban fringe area of Changchun City is extended to the east, southeast, and north. From 1995 to 2005, the outlying expansion was the dominant type. The main change mode was the infilling type due to the reduction of available land, from 2005 to 2015. In accordance with the landscape metrics, the landscape within the urban fringe transformed from fragmentation to regularization. The development of the urban fringe also transformed from a disorderly to an orderly manner.
\end{abstract}

Keywords: urban fringe; landscape metric; remote sensing; breakpoint method; Changchun

\section{Introduction}

Herbert Louis [1] proposed the concept of the "urban fringe area" (stadtrand zonen) in 1936. An urban fringe is located between an urban built-up and a rural area. The urban fringe area is transitional, gradual, and dynamic in numerous aspects, such as population, economy, land use, and ecology [2-4]. Depicted as a typical ecotone, an urban fringe plays an important role in urban evolution. China has previously undergone a dramatic urbanization process. The urbanization level was $49.9 \%$ in 2010 and reached $57.35 \%$ by 2016 [5]. The studies on the evolution of the urban fringe are significant in strengthening the orderly management of land resources and realizing the rational control of urban development and rural urbanization [6].

The primary task of an urban fringe region study is to execute the spatial recognition and boundary division of the urban fringe area. No uniform standard is available for the extraction of an urban fringe [6]. The urban fringe depicts significant differences between two continuous areas. Population diversity, and economic and social development factors are the most obvious characteristics of urban fringes in China [4,7]. Therefore, some scholars have adopted economic and social indicators to divide the urban 
fringe area. Researchers used fuzzy comprehensive evaluation method or a logistic regression model to define the urban fringe area, but these statistical data are updated slowly. In addition, the administrative boundary is also used as the statistical unit, which is not consistent with the reality of urban fringes [7-11].

The land use structure in an urban fringe is complex relative to the core area of a city. Therefore, an assessment based on the land use structure is feasible [12]. Remote sensing provides high-frequency earth observation data over a broad spatiotemporal scale in a spatially explicit manner [6]. Several scholars have conducted research on the urban fringe recognition method by using remote sensing data [13-16]. Different indexes, such as urban land use ratio, land use dynamic degree, and land use comprehensive index, are extracted and detected by mutation, and the urban fringe area is extracted. However, the selected indexes do not reflect the complexity of the land use structure in the urban fringe. Some studies apply the information entropy principle to determine the urban fringe through the threshold, but the selected threshold is subjective. The "breakpoint" analysis method proposed by Converse [17] in 1949 is mainly applied to determine the scope of the urban fringe. The basic principle is to select the maximum distance of the distance attenuation mutation of each element as the end of the flow and change. Therefore, this study combines the "breakpoint" method and the information entropy index in the extraction of urban fringe areas. The urban marginal area differs from the relatively stable natural geographic interface that often shows dynamic characteristics $[18,19]$. Thus, exploring the dynamic changes of urban fringe areas by using long-time series land use data is necessary.

Changchun is located in the hinterland of the Songliao Plain in northeastern China, facing the dual problems of economic development and environmental protection. The years since 1995 have seen population growth and economic development, with the strategy of revitalizing the old industry base in Northeast China. From 2010 to 2015, Changchun's central area measured $610 \mathrm{~km}^{2}$, which is only $0.25 \%$ of the total area of Jilin Province, but the total population increased from 3.13 million to 3.48 million, and the proportion of the total population in the province increased from $11.40 \%$ to $12.64 \%$. With the rapid development of urbanization, urban population and land gradually extended to the urban fringe [20]. The ecological environment in the urban fringe of Changchun is also facing threats. In 2009, the State Council formally approved the regional cooperation and development program involving the development of Tumen River and Changchun-Jilin-Tumen to signal the rise in construction in the area. In 2016, the State Council further approved the establishment of Changchun New Area, covering $499 \mathrm{~km}^{2}$, which has a rich water system, high forest coverage, and strong ecological sensitivity. Therefore, the study of the changes in the fringe area of Changchun is also significant for future spatial planning. In China, the 1994 tax reform stabilized the central government's revenue, but the revenue share of the local governments was not commensurate with the increased local responsibility. As land is a scarce resource in urban China compared with the abundant labor supply, selling land through rapid urban spatial expansion can meet the financial demands of local governments. For this reason, the land economy has become a main driving force in China's urbanization [1]. Thus, understanding the spatial-temporal patterns can provide valuable insights for planners and decision makers to plan and renovate the urban fringe.

Numerous studies have been conducted on the identification of urban fringes, but only a few studies have focused on their temporal and spatial characteristics [21,22]. This study uses Changchun, a rapidly growing city, as an example of evaluating the change dynamic characteristics of the urban fringe, in which land use data were acquired from remote sensing images. This study hopes to provide a methodical reference for urban fringe dynamic assessment and a highly accurate and scientific reference for urban planning.

\section{Study Area and Materials}

\subsection{Study Area}

Changchun City $\left(43^{\circ} 14^{\prime} \mathrm{N}-44^{\circ} 05^{\prime} \mathrm{N}, 125^{\circ} 03^{\prime} \mathrm{E}-126^{\circ} 00^{\prime} \mathrm{E}\right)$ is the capital of Jilin Province. It is considered the natural geographical center of northeastern China with an altitude of 250-350 $\mathrm{m}$ a.s.l. 
(Figure 1). The climate of Changchun is characterized by temperate continental monsoons with obvious seasonal variations. The highest temperatures were recorded in July (mean value: $23.1^{\circ} \mathrm{C}$ ), while the lowest were recorded in January (mean value: $-15.1^{\circ} \mathrm{C}$ ) [23]. The topography of Changchun is relatively flat, as it is a transitional zone between the eastern mountain area and the Songliao Plain in the west (W). The southeast (SE) part is a hilly low mountainous area with an elevation of more than $200-400 \mathrm{~m}$. The northwestern part is an alluvial platform, belonging to the undulating topography of the high plain (Figure 1).

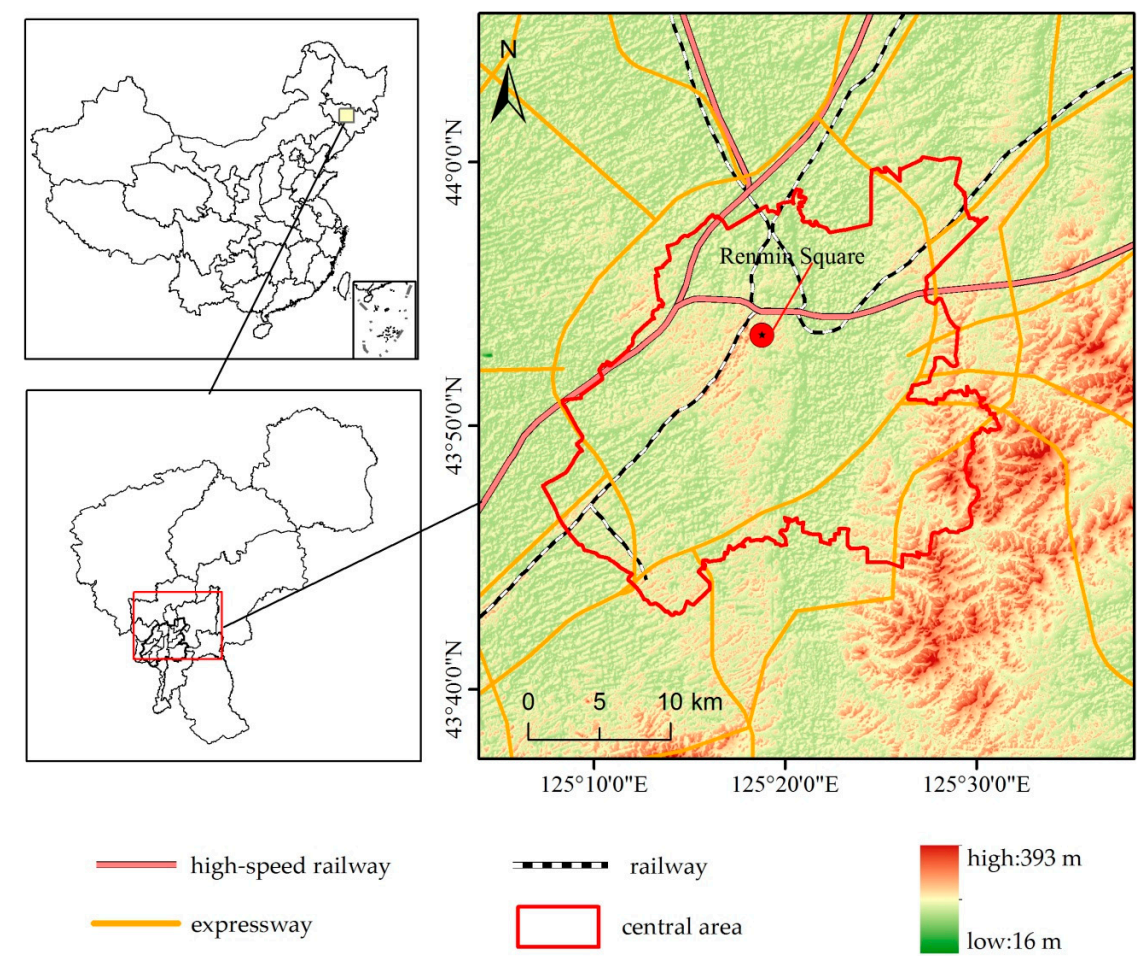

Figure 1. Location of the study area.

\subsection{Materials}

To establish the land use datasets, Landsat TM and Landsat Operational Land Imager (OLI) images were used for the land use classification. To cover the study region, two scenes of Landsat Multispectral Scanner (MSS) or Thematic Mapper (TM) data were acquired for each year (Table 1). Cloud-free satellite images from September to October were acquired when vegetation cover is at a maximum for each year. Radiometric calibration was performed for all of the images before they were delivered by the China Remote Sensing Satellite Ground Station (http:/ / www.rsgs.ac.cn).

Table 1. The satellite data used in the study.

\begin{tabular}{ccc}
\hline Sensor & Date & Path/Row \\
\hline Landsat-5 TM & 29 September 1995 & 118/29, 118/30 \\
Landsat-5 TM & 8 September 2005 & $118 / 29,118 / 30$ \\
Landsat 8 OLI & 22 October 2015 & 118/29, 118/30 \\
\hline
\end{tabular}

\section{Methodology}

\subsection{Land Use Classification}

The backdating approach is a synthesis of the post-classification comparison and pre-classification change detection. It typically starts with a reference map, and then, based on the map, classification 
and change analyses are conducted [24] only at locations with changes to maintain the consistency of the features $[25,26]$. In order to reduce the 'salt and pepper' effect, the backdating approach integrated with an object-based method was used for land use classifications. Five major land cover types and other land were found within the study area: forest, grassland, wetlands, farmland, and settlements. With this modified approach applied in this study, land use maps from 1995 to 2015 were generated through the following two steps:

Reference map production: The 2015 land use map was derived from 2015 Landsat OLI imagery using an object-based classification approach by the eCognition Developer 8.64 software. The work flow involved segmenting images, using a bottom-up region merging method [23], rule-building, and exporting vectors. After a trial and error process for testing the segmentation parameters, three levels of objects were created by setting parameters for different scales, the shape factor, and compactness factor, as shown in Table 2. Then, a decision tree approach was used and the rule sets were created based on the statistical analysis of the training areas resulting from the field surveys and images, including spectral information, spatial relations, and geometric characteristics (Figure 2). Visual interpretation and manual editing were conducted to further confirm the classifications for a highly accurate reference land use map. Accuracy assessment was conducted with ground survey data. The overall accuracy of the 2015 land use map was $92 \%$.

Table 2. Multi-scale segmentation parameters.

\begin{tabular}{cccc}
\hline Parameter & Level 1 & Level 2 & Level 3 \\
\hline Scale & 50 & 30 & 10 \\
Shape & 0.3 & 0.2 & 0.1 \\
Compactness & 0.4 & 0.4 & 0.4 \\
\hline
\end{tabular}



Figure 2. The outline of the decision tree. The threshold of each rule set varied with images. NDVI is the Normalized Difference Vegetation Index (NDVI), calculated from bands four and five of Landsat OLI; GLCM mean is the mean value of the gray level co-occurrence matrix and is widely used in textural features extraction, calculated by the gray scale value of the images. Elevation and slope are calculated from ASTER GDEM V1 data; NDWI is the Normalized Difference Water Index, calculated from bands three and five of Landsat OLI; NDBI is the Normalized Difference Build-up Index.

Land use map creation for other years: Using the 2015 land use map as the reference map, the land use classification maps for 1995 and 2005 were derived separately using an object-based backdating approach with change vector analysis. More details about the classification approach can be found in previous studies [24-26]. Accuracy assessment was also completed for the land use classification maps in 1995 and 2005 using historical field survey points and Google Earth images, as well as 
visual interpretation of the Landsat TM data as reference data. The overall accuracies of these three classification maps were 85\% for 1995, and $87 \%$ for 2005 .

\section{2. "Fringe Effect" and Land Use Information Entropy Model}

An ecotone, which is a transition area between two biomes or different patches of landscape, has increased biodiversity, referred to as the "fringe effect," as it provides significant spatial and temporal variation in resources $[3,22,27,28]$. Information entropy is the physical quantity used to measure the complexity and balance of the system, and is applied to the study of land use landscape pattern recognition and the establishment of landscapes. In accordance with the Shannon diversity index (SHDI), the entropy model of land use can be established as follows [29,30]:

$$
\mathbf{H}=-\sum_{i=1}^{n} p_{i} \ln p_{i}
$$

where $\mathbf{H}$ is the diversity index (information entropy value). $p_{i}$ denotes the proportion of area covered by land cover class $i$, and quantifies the diversity of land cover type on basis of two components: number of different land cover types (richness) and proportional area distribution among land cover types (evenness). The more land types per unit area, the higher the heterogeneity of land use patches and the greater the SHDI. Urban and rural areas mostly include built-up areas or agricultural land. When land use types are singly used, the SHDI is low. However, the biggest feature of the urban fringe is the diversity of land use types, that is, land use types are interlaced and the layout is loose, and thus, SHDI is high $[31,32]$.

By using remote sensing technology, the dynamic and fine-scale monitoring of the change of land use structure in urban areas can be monitored. In comparison with the method of extracting the edge area by using the ratio of built-up area, SHDI can reveal the homogeneity and heterogeneity of landscape spaces and quantify the dispersion and fragmentation degree of urban landscapes. SHDI is influenced by the scale variation and selecting an optimal scale for calculating and analyzing the land cover information entropy is essential to further preserve the pattern and reduce data redundancy [7]. In accordance with previous studies [7], the 960-meter scale is the optimal scale for land use data interpreted by using Landsat. The research area was divided into 4154 grids of size $960 \mathrm{~m} \times 960 \mathrm{~m}$. The area ratios of the different use types of each grid were calculated, and then, the SHDI values of the corresponding grid were calculated in accordance with Equation (1).

\subsection{Extraction of Breakpoints of SHDI in 360 Directions}

By using Renmin Square in Changchun as the center and starting point of the east direction, 360 profile lines were created at intervals of $1^{\circ}$ to cover the entire research area. The longest distance, from Renmin Square to the boundary of Changchun's municipal area, was used as the radius. Figure 2 shows that the profile lines cover the entire study area. After the SHDI characteristic was intersected with the 360 profile lines, the corresponding data in 360 directions of the study area were obtained $[2,11]$. This operation was implemented by using ArcGIS (Figure 3).
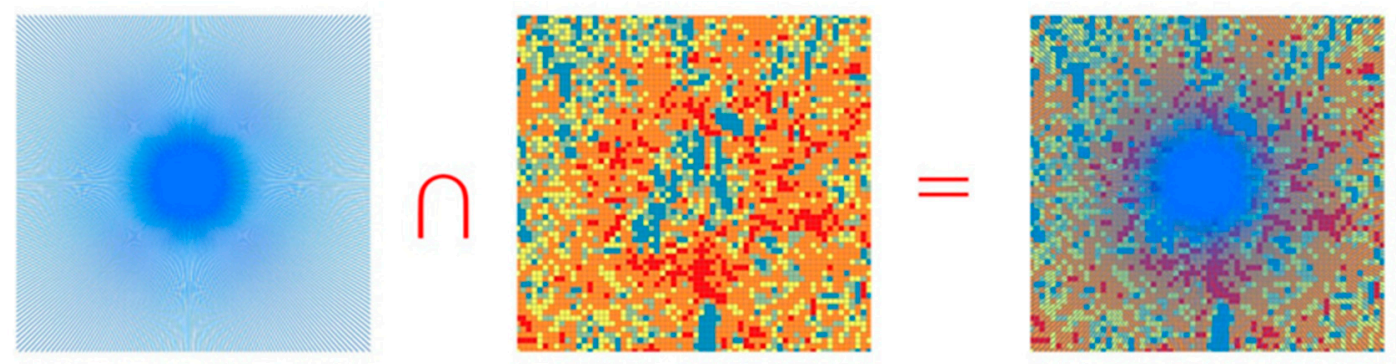

Figure 3. Schematic diagram of the data columns derived in 360 directions. (The center of the circle is blurred because the 360 lines are too dense.) 
In this study, the breakpoints were detected by using SHDI, to prevent the irregular change of SHDI in some places. This study adopted the window sequence method. In any direction, $L$ denotes the sequence length, $S_{i}$ represents the SHDI value of a sequence, and $\mathbf{N}$ is the total number of windows in the direction. The change rate and distance attenuation mutation value are calculated as follows [2,33]:

$$
\begin{gathered}
V_{i}=\left|S_{i+1}-S_{i}\right| / L \\
\mathrm{~V}=1 / \mathrm{N} \sum_{i=1}^{N} V_{i} \\
D D V_{i}=V_{i} / V
\end{gathered}
$$

The SHDI value of each direction obtained by the method for intersect analysis was exported. By using Renmin Square as the starting point, the attenuation mutation value of each point is calculated by using MATLAB. The pixel in a certain direction with the maximum $D D V_{i}$ was the breakpoint. Breakpoints were displayed over the filled contour maps of SHDI. The inner and outer boundary lines of the urban-rural fringe areas were obtained by measuring the distance between the breakpoints and the center of the study area. Consequently, the abnormal mutation points were eliminated, and the breakpoints were connected with curves.

By using remote sensing technology, the dynamic and fine-scale monitoring of the change of land use structure in urban areas can be monitored. In comparison with the method of extracting the edge area by using the ratio of built-up area, SHDI can reveal the homogeneity and heterogeneity of landscape spaces and quantify the dispersion and fragmentation degree of urban landscapes. SHDI is influenced by the scale variation and selecting an optimal scale for calculating and analyzing the land cover information entropy is essential to further preserve the pattern and reduce data redundancy [7]. In accordance with previous studies, the 960-meter scale is the optimal scale for land use data interpreted by using Landsat. The research area was divided into 4154 grids of size $960 \mathrm{~m} \times 960 \mathrm{~m}$ [7]. The area ratios of the different use types of each grid were calculated, and then, the SHDI values of the corresponding grid were calculated in accordance with Equation (1).

\subsection{Urban Fringe Fragmentation Dynamic Metric}

This study on urban fringe was assessed by using landscape metrics at the landscape level. Five metrics were obtained to indicate urban fragmentation (Table 3): patch density (PD), mean patch size (MPS), edge density (ED), mean perimeter-area ratio (MPAR), and area-weighted mean shape index (AWMSI). The five metrics can describe urban fragmentation from different aspects [34-36]. PD is the ratio between urban land patch number and total land area, and it describes the density of land use and the extent of fragmentation. ED measures the total edge lengths divided by the total land area. AWMSI is a measure of shape complexity. Metric calculations were conducted with Patch Analyst $5.1[37,38]$.

Table 3. Selected landscape metrics.

\begin{tabular}{cccc}
\hline Metrics & Unit & Range & Description \\
\hline PD & per 100 hectare & NP $\geq 0$ & Number of patches per 100-hectare landscape \\
MPS & Hectares & MPS $>0$ & Average patch size \\
MPAR & $\%$ & MPAR $>0$ & Mean perimeter-area ratio, all patches \\
ED & Meters per hectare & ED $\geq 0$ & Amount of edge relative to the landscape area \\
AWMSI & None & AMMSI $\geq 1$ & $\begin{array}{c}\text { AWMSI is equal to 1 when all patches are circular and } \\
\text { increases with increasing patch shape irregularity }\end{array}$ \\
\hline
\end{tabular}




\section{Results and Discussion}

\subsection{Land Use Transition in Central Area}

From the perspective of spatial distribution, settlements and farmland are the main land use types in the central area, followed by forest. From 1995 to 2005, the change of land use in Changchun was dramatic. The city extended to the E, SE, and southwest (SW). Furthermore, the surrounding farmland was converted into settlements (Figure 4). The area of settlements in the central area increased from $213.73 \mathrm{~km}^{2}$ to $379.70 \mathrm{~km}^{2}$, which increased by $77.65 \%$, and the average growth was $16.60 \mathrm{~km}^{2}$ per year. Along the road, a large area of farmland converted to settlements was also observed. The increase of forest area was mainly due to the conversion of other land use types in the SW part. During 2005-2015, the city continued to spread to the northeast (NE), SE, and SW, the speed of urban expansion slowed down, the area of settlements increased to $412.84 \mathrm{~km}^{2}$, the annual increase was $3.31 \mathrm{~km}^{2}$, and the main type of change was farmland conversion to settlements.

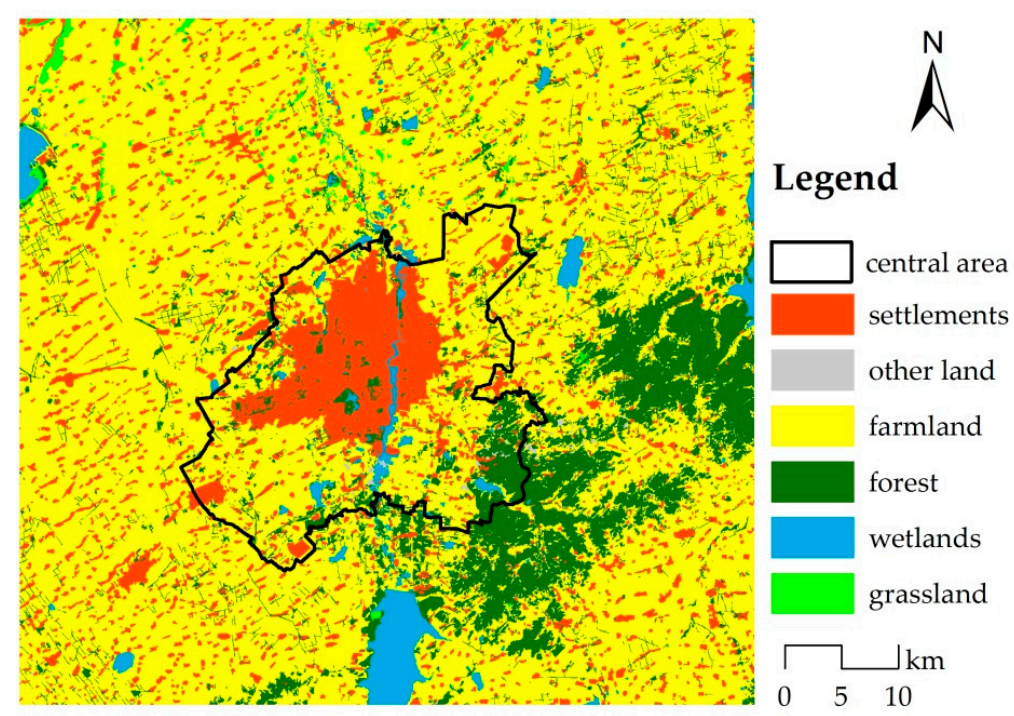

(a) 1995

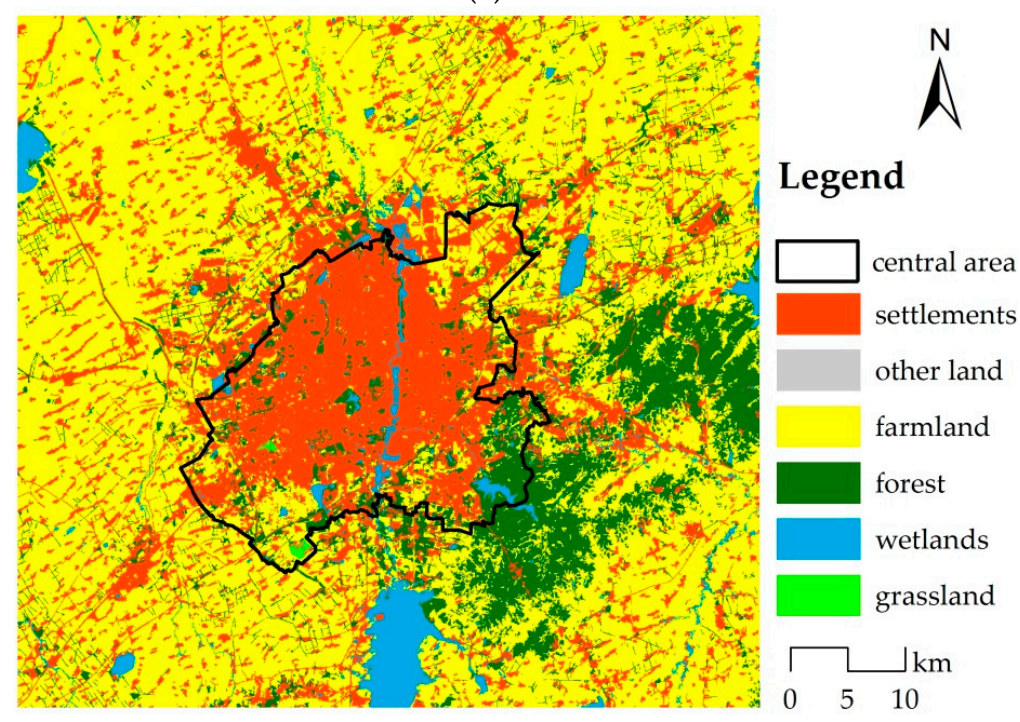

(b) 2005

Figure 4. Cont. 


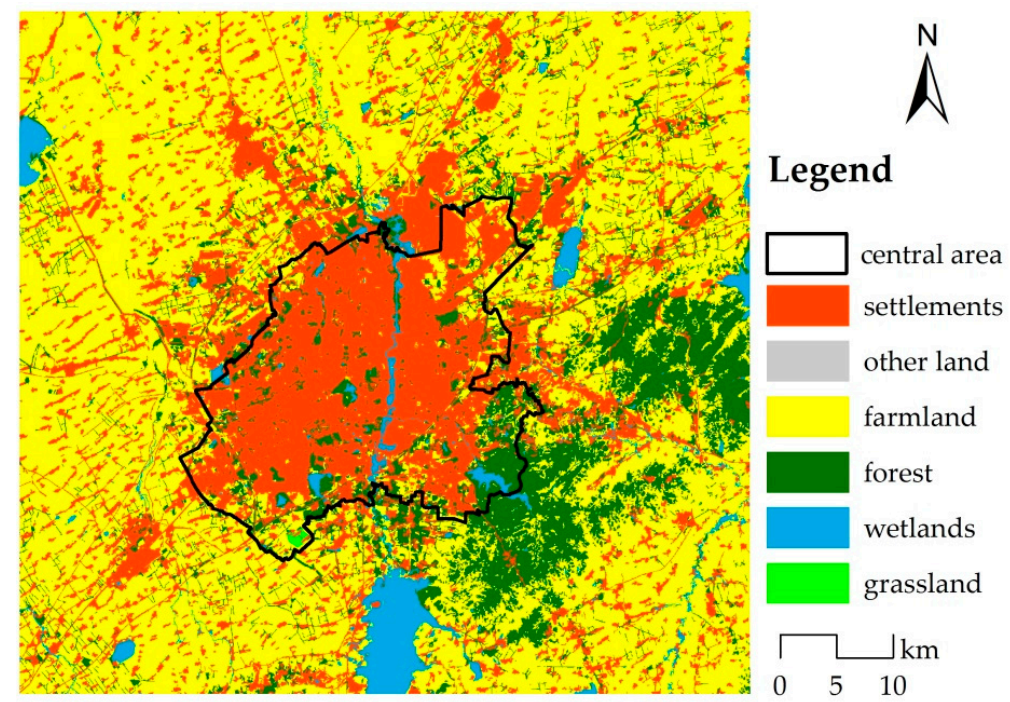

(c) 2015

Figure 4. (a-c) Land use in Changchun (1995-2015).

The land use structure changed significantly during 1995-2005, and the proportion of settlements increased from $35.04 \%$ to $62.50 \%$, whereas the proportion of farmland areas declined from $48.05 \%$ to $17.76 \%$. The proportion of forest increased from $12.97 \%$ to $16.17 \%$. From 2005 to 2015 , the proportion of different land use types changed slowly. The main change was that the proportion of land use continued to grow to $67.69 \%$, and the proportion of farmland decreased to $11.83 \%$ (Figure 5).

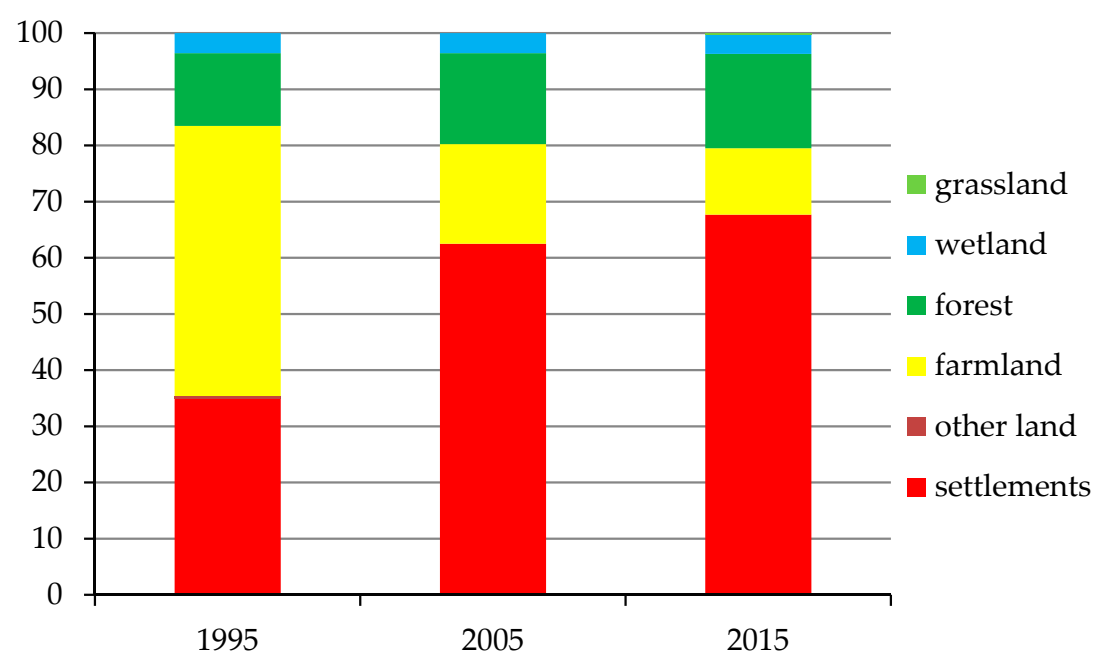

Figure 5. Changes in the proportion of different land use types (1995-2015).

\subsection{Quantitative Change Characteristics}

In 1995, 2005, and 2015, the urban fringe areas of Changchun were 269.72, 773.03, and 802.85 $\mathrm{km}^{2}$, respectively (Figure 6). The urban core areas of Changchun were 108.84, 262.97, and $367.12 \mathrm{~km}^{2}$, respectively. From 1995 to 2015, the core area of Changchun increased by $258.28 \mathrm{~km}^{2}$ at the rate of $237.30 \%$. The urban fringe area increased by $533.13 \mathrm{~km}^{2}$ at the growth rate of $197.66 \%$. The growth rate of the urban core area was lower than that of the urban fringe area, and the degree of expansion of the urban fringe was higher than that of the core area (Table 4). 


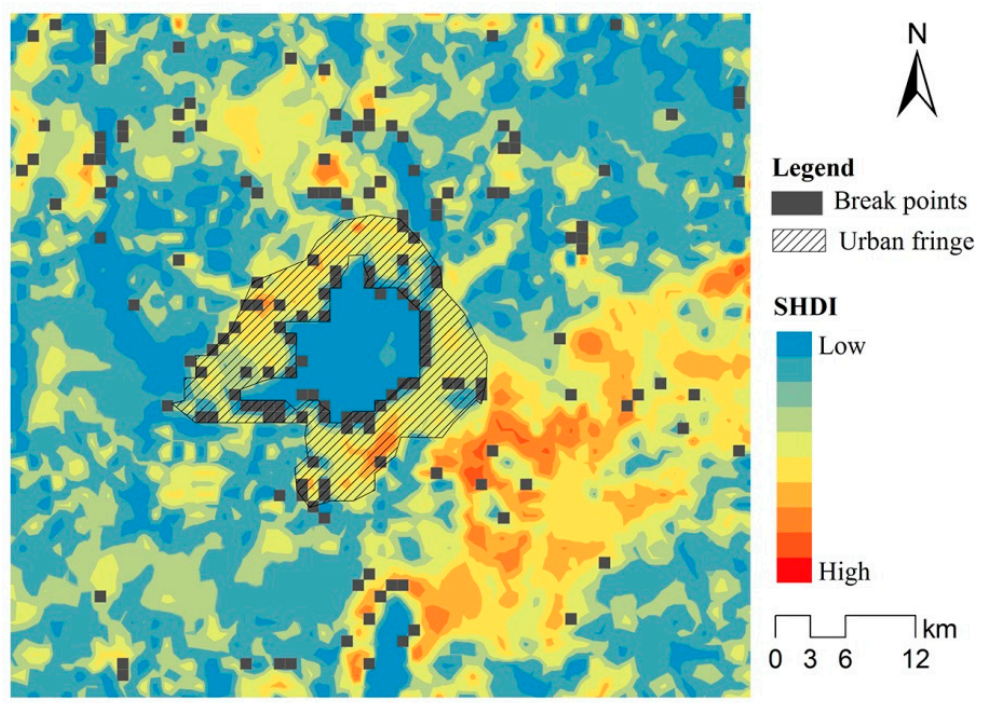

(a) 1995
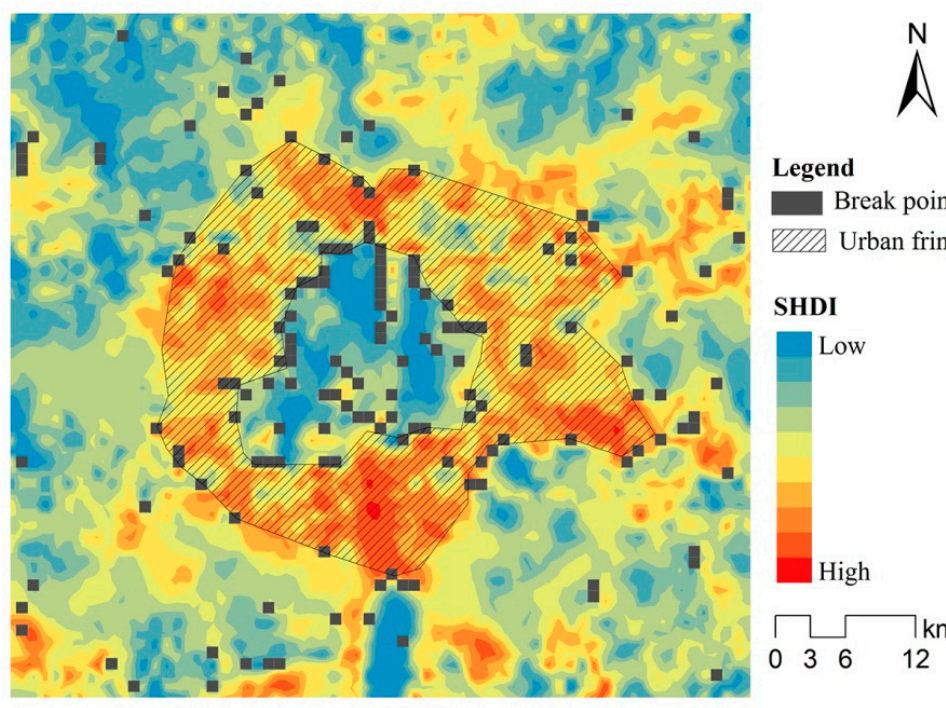

Legend

Break points

VII Urban fringe

SHDI

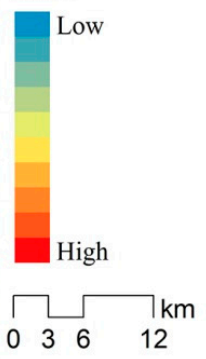

(b) 2005
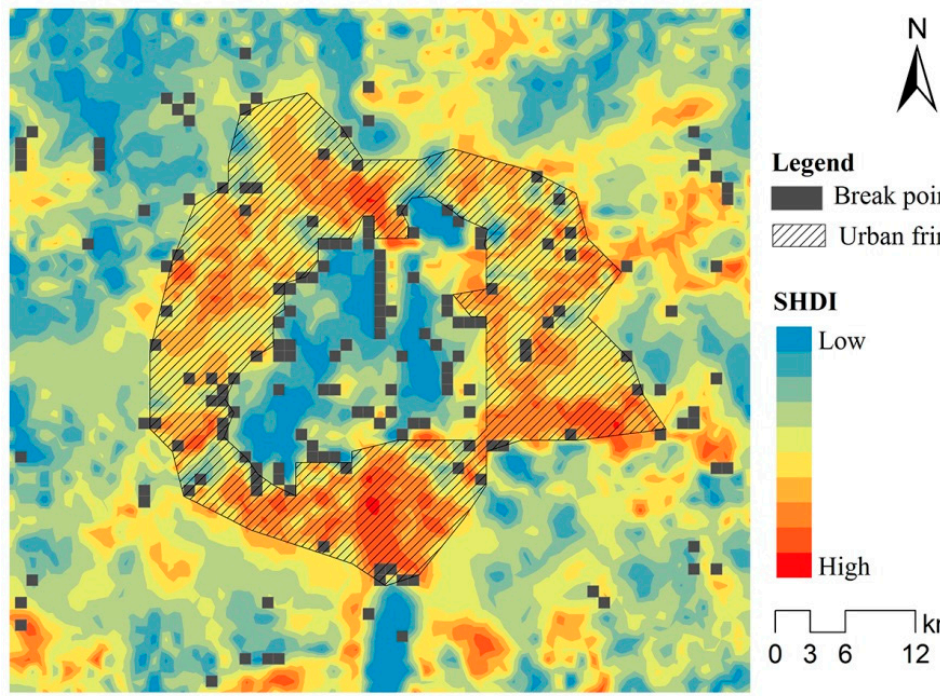

Legend

Break points

VIIA Urban fringe

SHDI

(c) 2015

Figure 6. (a-c) Distribution of urban fringes (1995-2015). 
Table 4. Quantitative status of the expansion in the urban fringe of Changchun (1995-2015).

\begin{tabular}{|c|c|c|c|c|c|c|}
\hline \multirow[b]{2}{*}{ Period } & \multicolumn{3}{|c|}{ Urban Core Area } & \multicolumn{3}{|c|}{ Urban Fringe } \\
\hline & $\begin{array}{c}\text { Expanding } \\
\text { Amount }\left(\mathrm{km}^{2}\right)\end{array}$ & $\begin{array}{c}\text { Expanding } \\
\text { Rate (\%) }\end{array}$ & $\begin{array}{c}\text { Expanding } \\
\text { Speed }\left(\mathrm{km}^{2} / \mathbf{a}\right)\end{array}$ & $\begin{array}{c}\text { Expanding } \\
\text { Amount }\left(\mathbf{k m}^{2}\right)\end{array}$ & $\begin{array}{l}\text { Expanding } \\
\text { Rate }(\%)\end{array}$ & $\begin{array}{c}\text { Expanding } \\
\text { Speed }\left(\mathrm{km}^{2} / \mathrm{a}\right)\end{array}$ \\
\hline 1995-2005 & 154.13 & 141.61 & 15.41 & 503.31 & 186.60 & 50.33 \\
\hline 2005-2015 & 104.15 & 39.61 & 10.42 & 29.82 & 3.86 & 2.98 \\
\hline 1995-2015 & 258.28 & 237.30 & 12.91 & 533.13 & 197.66 & 26.66 \\
\hline
\end{tabular}

During the first period (1995-2005), the urban core area increased by $154.13 \mathrm{~km}^{2}$, whereas the urban fringe increased by $503.31 \mathrm{~km}^{2}$ (i.e., 3.27 times the growth of the core area). From 2005 to 2015 , both growth rates of the urban core and the urban fringe decreased, by which the growth rate of the urban fringe was lower than that of the urban core.

Economic development and population growth, which are the basic driving forces of urban expansion, are also major factors affecting the land use change in the urban fringe area. During 1995-2005, the growth of urban fringe was closely related to the speed of urban expansion. The average annual growth rate of gross domestic product (GDP) in Changchun was $31.13 \%$, with an annual population increase of 64.2 thousand persons (Figure 7). The development of urban economy needs the support of space. The increase of population will strengthen the urban residents' demand for housing, transportation, and public facilities and then expand the urban land to the outside, thereby significantly changing the land structure around the city and increasing the border area. In total, in the second stage, that is, during 2005-2015, GDP and population growth slowed, especially after 2010 when the population of Changchun declined, the demand for urban space declined, and the growth rate of urban fringe areas decreased accordingly.

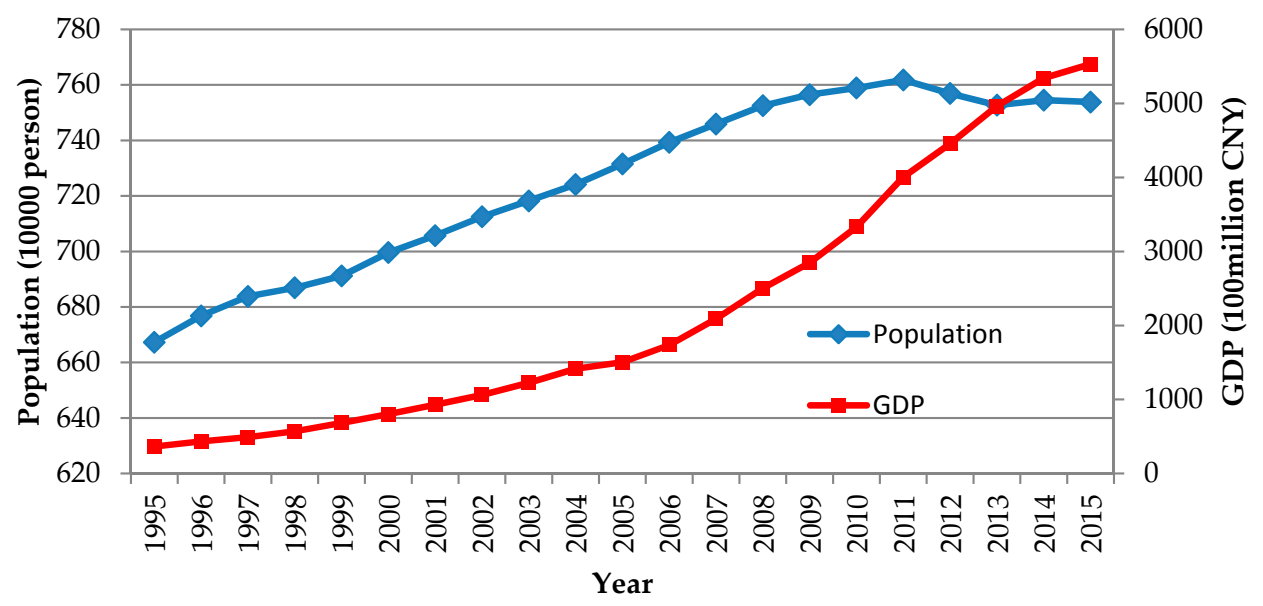

Figure 7. GDP and population of Changchun (1995-2015).

\subsection{Expansion Direction}

To analyze the expansion pattern of the urban fringe in different directions in the study area and explore the factors that affect the expansions of urban fringe, eight expansion directions were compared (Figure 8): E, NE, SE, south (S), SW, W, northwest (NW), and north (N).

From 1995 to 2005, the outlying expansion mainly occurred in the E, SE, and S directions. The area of eastward expansion was $135.39 \mathrm{~km}^{2}$, which accounted for $21.23 \%$ of the total expansion area. The main areas of infilling change were concentrated in the W, SW, and NW directions. The region converted to core area was mainly located in the SE, which accounted for approximately $23.99 \%$ of the total converted area. 
From 2005 to 2015, the urban fringe area mainly extended northward with an area of $40.09 \mathrm{~km}^{2}$, which accounted for $27.75 \%$ of the total area. Except for the NE direction, the amount of infilling in the remaining directions was all large. The top two values of the core area conversions toward the NE and E directions were 26.62 and $26.12 \mathrm{~km}^{2}$, respectively.

In general, during 1995-2015, the urban fringe area of Changchun mainly extended to the E, SE, and $\mathrm{N}$ directions. The infilling changes mainly occurred in the $\mathrm{W}$ and SW parts of the city. The amounts of urban fringe converted into core area in the SE and S parts of the city were the top values (Figure 8).
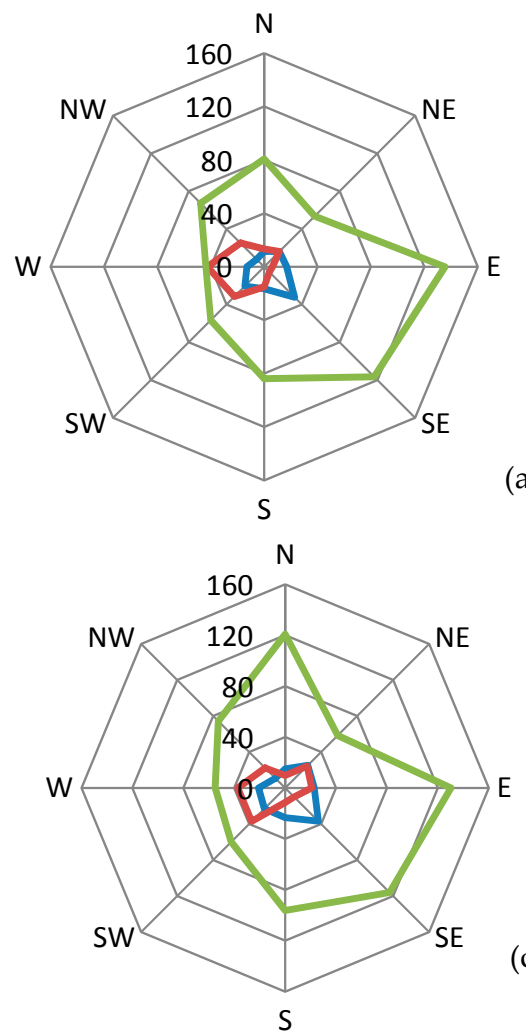

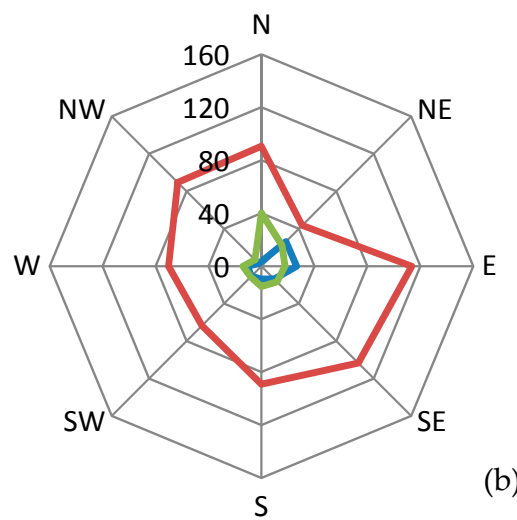

(b) (a)

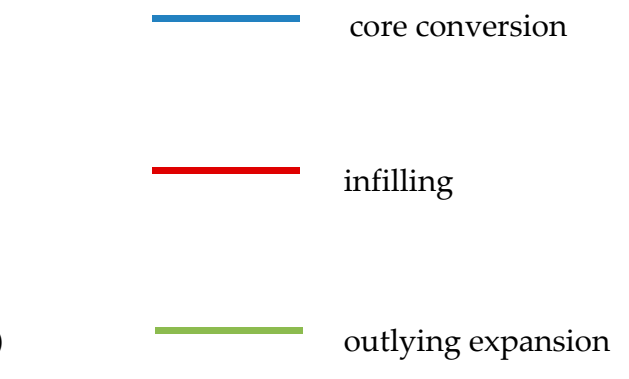

Figure 8. Distribution of expansion types in different directions of the urban fringe in Changchun (1995-2015). (a) 1995-2005; (b) 2005-2015; (c) 1995-2015.

A development zone refers to a specific area of a country or region to attract external factors of production, promote its own development, and implement special policies and management in a certain area. The development zone plays an important role in the development of Changchun City. In 1991, Changchun City established high-tech development zone. The Economic and Technological Development Zone was set up in 1993, and the Jingyue Tourism Development Zone was established in 1995. In 2016, the State Council further approved the establishment of Changchun New Area (Figure 9). Usually, enterprises in the development zone can get land use rights at lower prices and enjoy tax concessions. As the development zone has preferential policies for investment and construction, it has promoted the agglomeration of enterprises and population in the region. The exuberant demand for land is the main factor that causes the urban fringe of Changchun to expand to the E, SE, and SW during 1995-2015. The direction of urban fringe expansion is closely related to the distribution of development zones.

The urban master plan of the 1995 edition suggested that the urban layout structure adopts the decentralized group style, and clearly put forward the transfer of urban development from the center to the fringe, from the old urban region to the new area. The urban master plan of the 2005 edition put forward the spatial structure of "dual-core, multi-level and eight areas". "Dual-core" refers to the 
establishment of new town in the southern part of the city. Under the guidance of this plan, Changchun extended to the south. In 2011, the master plan of Changchun put forward the urban spatial structure of "dual-core, two wings and multi-group", transferred some functions of the central urban area to other areas, and formed two urban centers in the central and southern part. The planning of urban spatial structure leads the city to expand towards the $\mathrm{S}$ and the $\mathrm{E}$, and promoted the expansion of the urban fringe in the SW, SE, and E.

The development of the economy has promoted the construction of the road in the region. The road is the main medium to contact the cities and peripheral areas. The expressway in the $\mathrm{E}$ of Changchun is dense and also promotes the expansion of the urban fringe area of Changchun to the E.

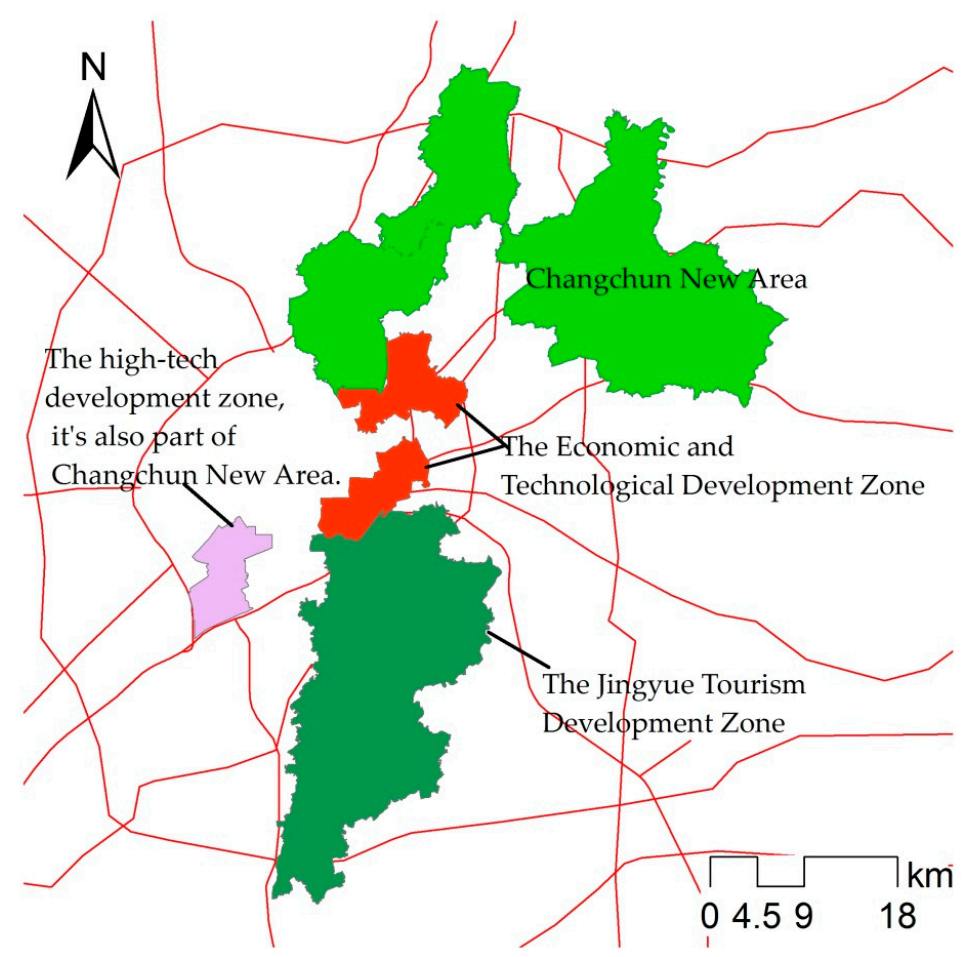

Figure 9. Distribution of development zones of Changchun.

\subsection{Change Mode}

On the basis of existing research, the expansion of the urban fringe area is divided into three types. The outlying expansion type is transformed from the rural hinterland of the previous period into the region of the urban fringe of the current period. The infilling type depicts a region belonging to the urban fringe area between two periods (previous and current). However, in the interior, where land use type changes have happened, the core conversion type is an appropriate descriptor, that is, the transformation from an urban fringe to a core area of the city $[14,35]$.

In general, from 1995 to 2015 , the main change type of the urban fringe was outlying expansion. The number of urban fringe areas converted into core areas was considerably smaller than the increase in urban fringe area (Figure 10). The characteristics of topographic relief are often the basic skeleton of the large-scale regional distribution pattern. During 1995-2015, the restraining effect on the urban spatial expansion of Changchun is becoming increasingly prominent. The eastern part of Changchun City is a hilly land, and the land available for urban use is reduced. The infilling changes in the urban fringe increased in the SE direction. 


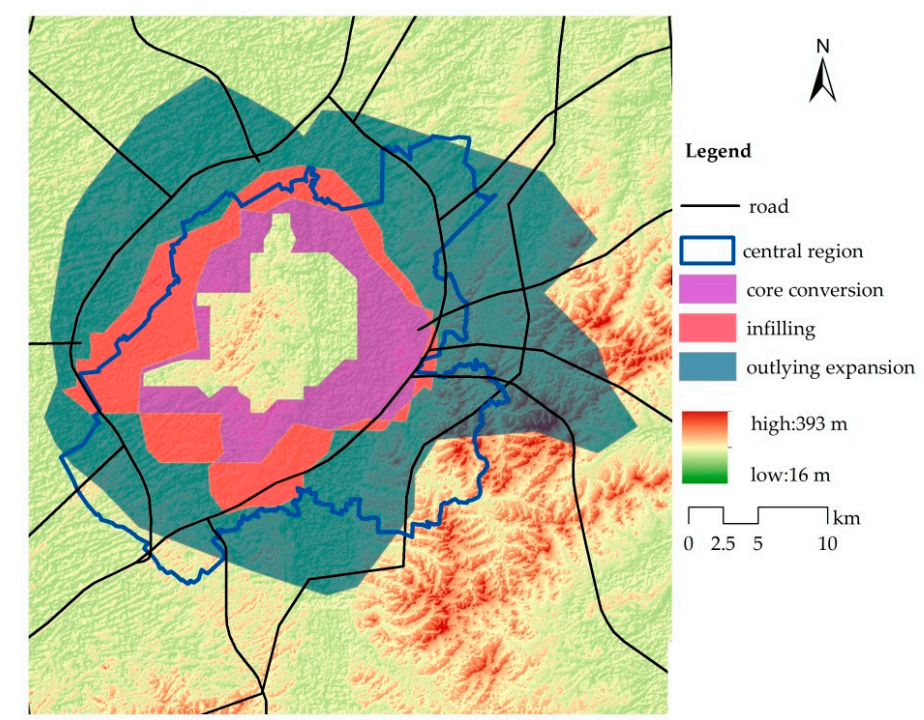

(a) 1995-2005

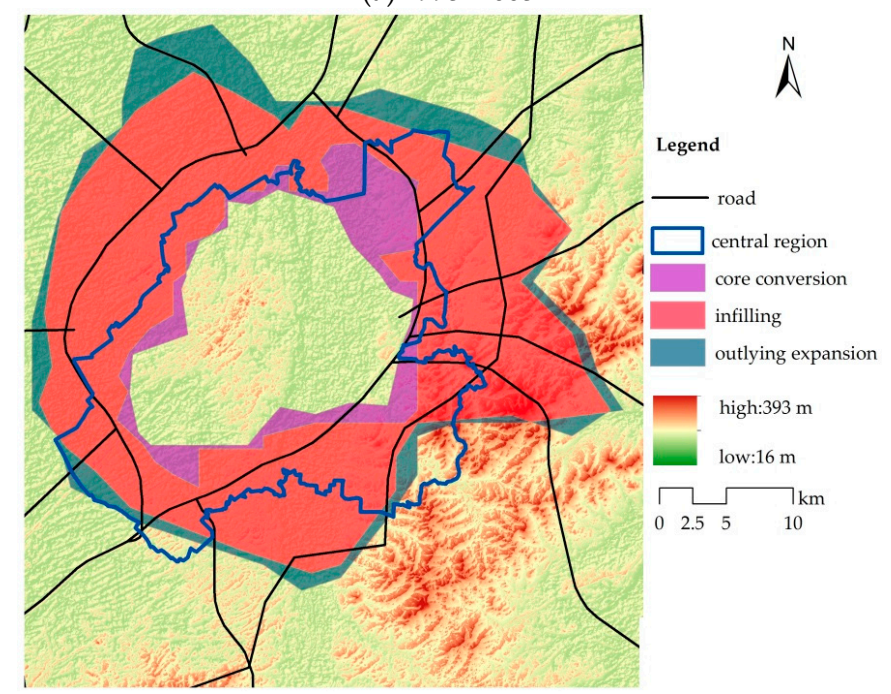

(b) 2005-2015

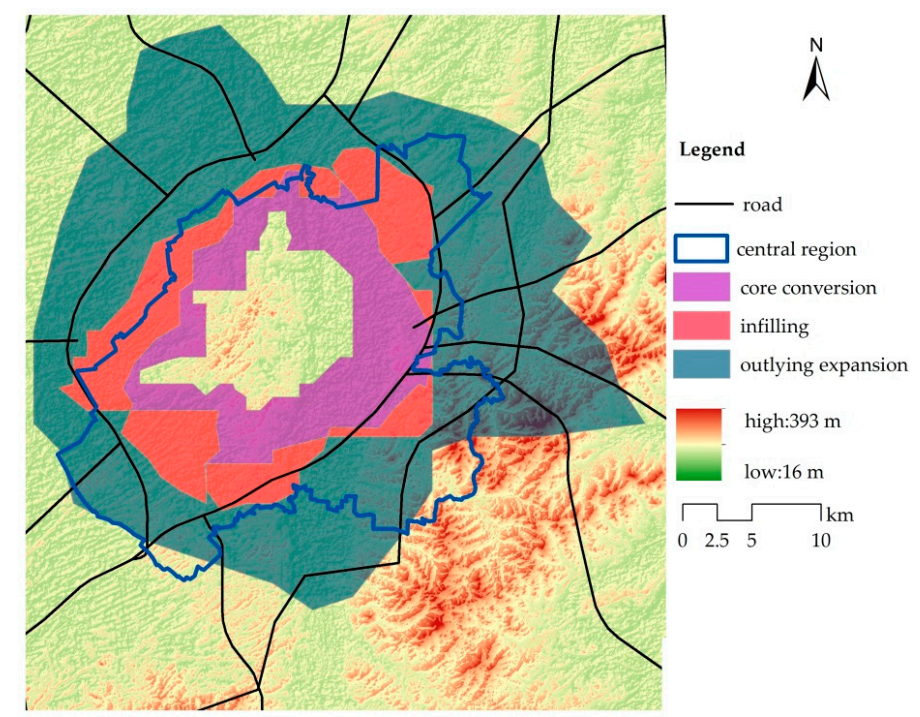

(c) 1995-2015

Figure 10. (a-c) Distribution of change types in the urban fringe of Changchun (1995-2015). 
From 1995 to 2005, the urban fringe of the outlying expansion reached $637.78 \mathrm{~km}^{2}$, which accounted for $82.50 \%$ of the total urban fringe in 2005. The infilling area was $155.70 \mathrm{~km}^{2}$, which accounted for $57.7 \%$ of the total area in 1995. A total of $134.48 \mathrm{~km}^{2}$ of urban fringe was transformed into a core area, which accounted for $51.14 \%$ of the total core area in 2005 . In this phase, the urban fringe change mode was dominated by outlying expansion (Figure 11).

From 2005 to 2015, the urban fringe of the outlying expansion reached $144.49 \mathrm{~km}^{2}$, which accounted for $18 \%$ of the total area in 2015. The infilling area was $663.62 \mathrm{~km}^{2}$, which accounted for $85.85 \%$ of the total area in 2005. The urban fringe area transformed into a core area covering $177.80 \mathrm{~km}^{2}$, which accounted for $48.43 \%$ of the total core area in 2015. In this phase, the urban fringe area was dominated by infilling types (Figure 11).

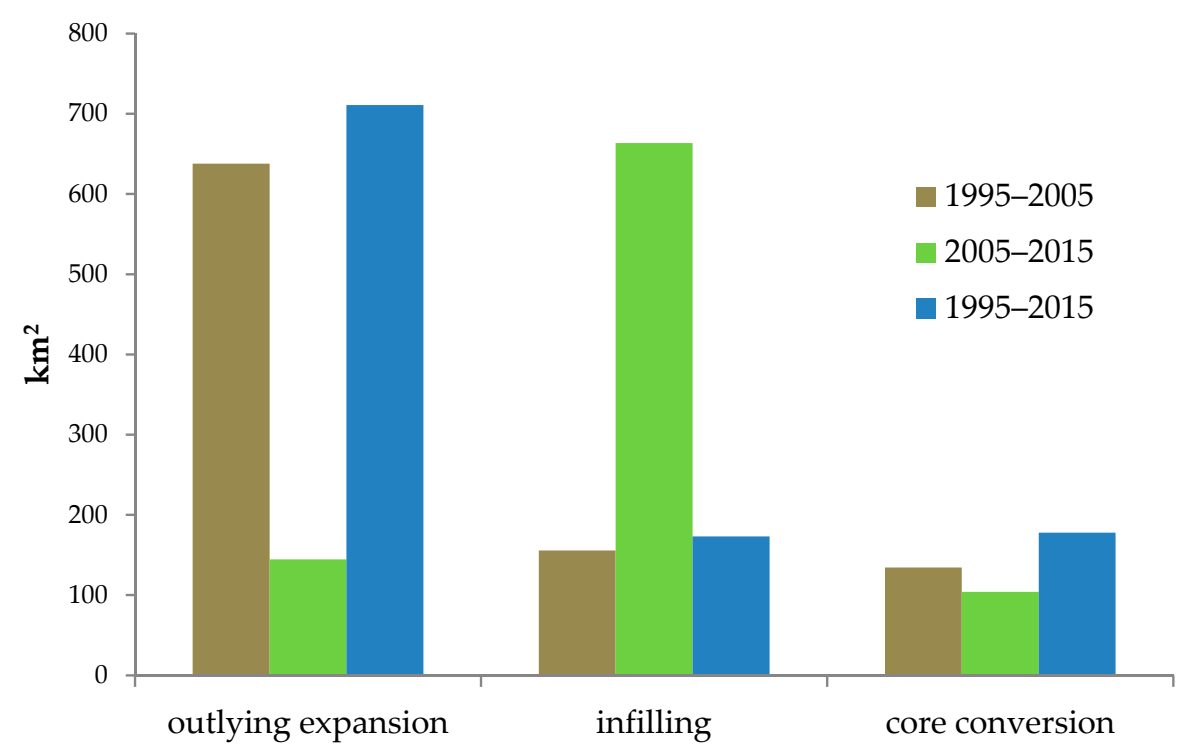

Figure 11. Areas of different change types (1995-2015).

The characteristics of topographic relief are often the basic skeleton of the large-scale regional distribution pattern. During 1995-2015, the restraining effect on the urban spatial expansion of Changchun became increasingly prominent. The eastern part of Changchun City is hilly, and the land available for urban use is reduced. The infilling changes in the urban fringe increased in the SE direction.

\subsection{Changes in Urban Fringe Fragmentation}

The land uses and landscapes in the urban fringe area have unique characteristics. The process involved outlying expansion, infilling, and core conversion, and thus, the inner landscape of the urban fringe changed significantly.

Figure 12 shows the change rate from using the previously selected landscape metrics above. PD values increased sharply and declined slightly, whereas MPS values declined sharply and increased slightly from 1995 to 2005, which indicates that human activities significantly influenced the urban fringe during this period. The original types of land use changed, the density of patches in the urban fringe increased, and the average patch area decreased. Moreover, the relatively dense patches and the increased average patch sizes from 2005 to 2015 indicate that land use in the urban fringe areas has shifted from disorderly to orderly development. 


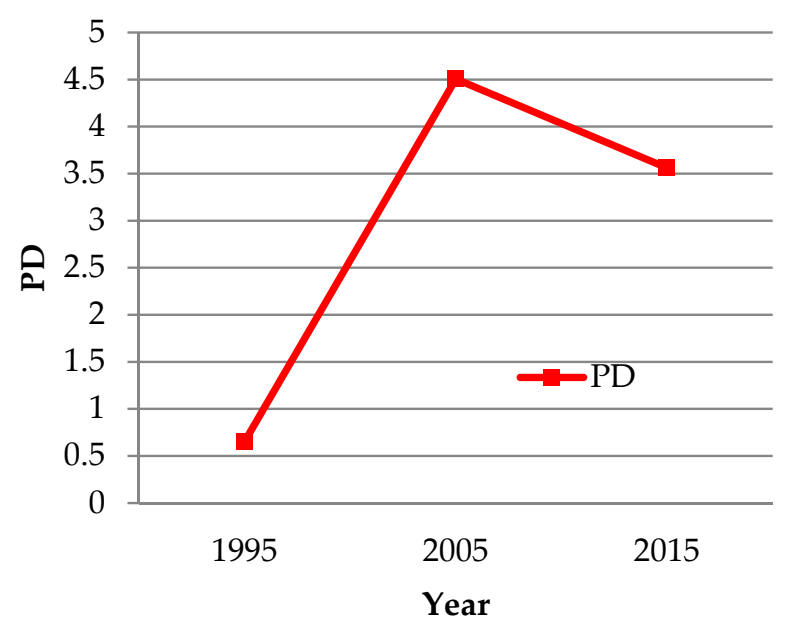

(a)

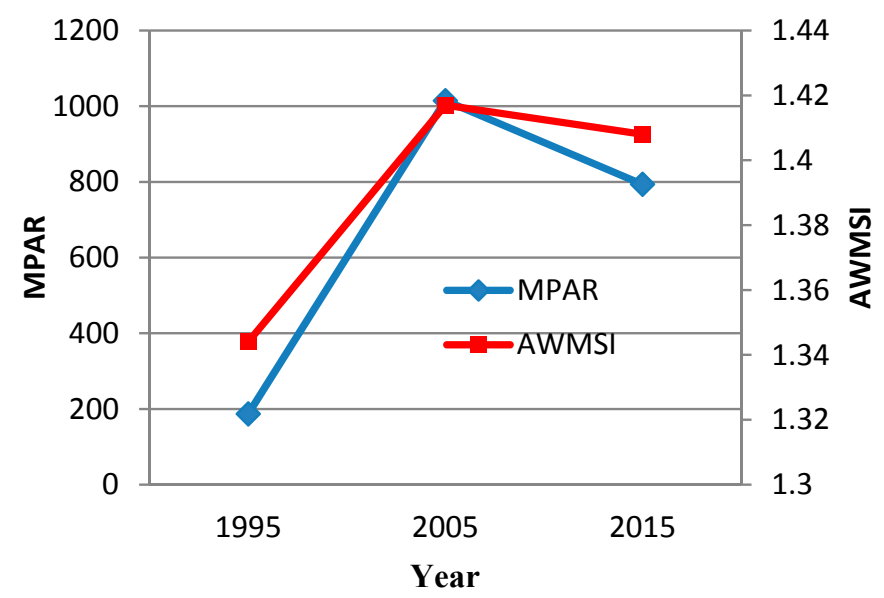

(b)

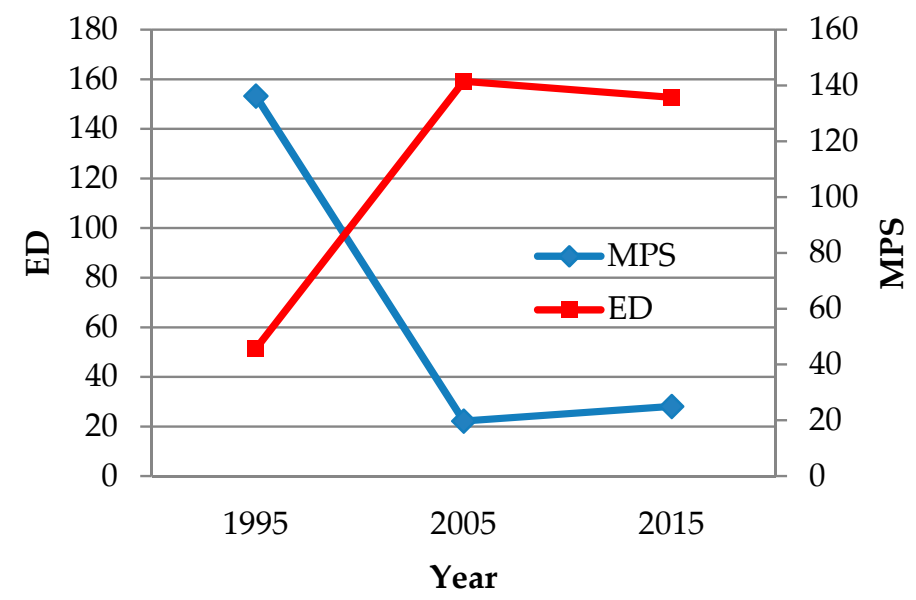

(c)

Figure 12. Changes of different landscape metrics (1995-2015). (a) Changes of PD; (b) Changes of MPAR and AWMSI; (c) Changes of ED and MPS.

MPAR, AWMSI, and ED values increased sharply and declined slightly from 1995 to 2005. Land fragmentation resulted in irregularly shaped land patches, but the patches started to develop regularly 
from 2005 to 2015. In accordance with the results of the landscape indicators, the landscape of Changchun's urban fringe is significantly affected by urban expansion, which reflects the utilization process of the natural landscape from disorderly to orderly development. The landscape index shows that the urban fringe area of Changchun has experienced two stages: the urban growth speed was high during 1995-2005, and disordered. However, during 2005-2015, the available land around settlements reduced. Attention has been paid to the value of land use at the edge of the city, and orderly development and construction have begun.

Under the current land management system in China, the scale of urban construction land cannot exceed the provided quantity of the master plan. In the master plan of Changchun in 1995, the land allowed for construction was $391 \mathrm{~km}^{2}$, and the built-up area recognized by remote sensing was only $213 \mathrm{~km}^{2}$. Changchun had sufficient land for construction, and the land use in the urban fringe was disorderly. By 2005, the built-up area recognized by remote sensing had reached $379 \mathrm{~km}^{2}$, which was close to the upper limit of the area provided in the master plan of 1995. The master plan of the new edition adjusted the permitted area to $445 \mathrm{~km}^{2}$ in 2011. During 2005-2015, only $66 \mathrm{~km}^{2}$ could be used for construction in Changchun (Figure 13). Overall, from 2005 to 2015, the land available in Changchun was scarce, and the infilling growth in the urban fringe areas provided valuable land for urban construction.

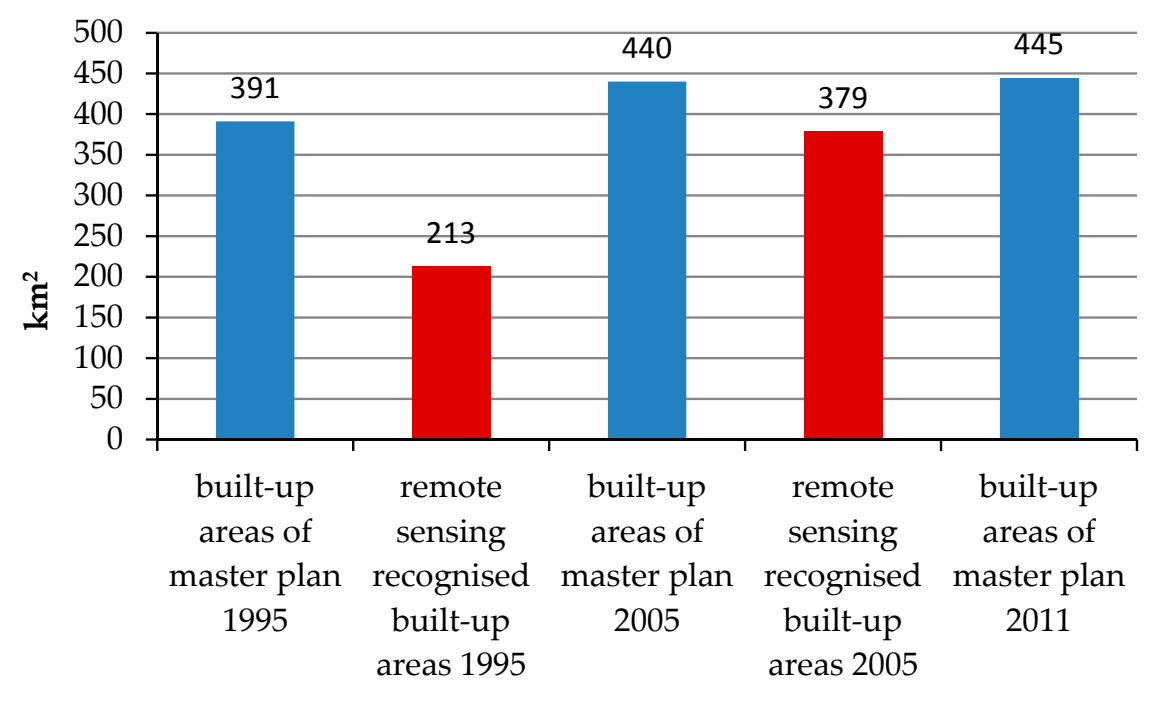

Figure 13. Built-up areas of master plan and built-up areas recognized by using remote sensing images.

\subsection{Implications for the Construction of Changchun New Area}

The available land around the central urban area is insufficient. With the establishment of Changchun New Area, a large amount of construction land has been provided for Changchun, and the city will expand to the NE. A new urban fringe will appear. In the past, urban construction land planning belongs to the Planning Bureau, farmland pertains to the Land Bureau, woodland and wetlands correspond to the Forestry Bureau, and grassland is associated with the agricultural sector. The spatial planning is inconsistent, and the problem in the urban fringe is further prominent. In 2018, the State Council promoted institutional reform, set up the Ministry of Natural Resources, and proposed that a unified spatial planning system should be established. In the future development of Changchun New Area, attention must be paid to the sustainable development of land use in the urban fringe area.

\section{Conclusions}

An urban fringe area is a region where both social and environmental problems are concentrated. The identification and evaluation of urban fringe spatial distribution are the foundation for this work. China is in a state of rapid urbanization. On the basis of the land use data extracted from remote 
sensing data, identifying the urban fringe area with SHDI and the breakpoint method is reliable, and the results can be used as a reference for urban fringe studies in other cities.

Changchun, similar to other cities, is undergoing rapid growth. In this study, three types of land use data were extracted from remote sensing images. On the basis of the entropy information of land use, the scope of the urban fringe of Changchun City in 1995, 2005, and 2015 was identified with the breakpoint method. The changes in the number of urban fringe areas, the change mode, and the changes in landscape metrics in the urban fringe were evaluated.

Policy and planning are the main factors influencing the development of Changchun fringe area. Since 1991, the establishment and construction of three development zones in Changchun have affected the expansion direction of the urban fringe area. From 1995 to 2015, the urban fringe areas mainly extended to the E, SE, and N. The changes in infilling type mainly occurred in the W and SW, and the core conversion areas were mainly in the SE and S. The results from the landscape metrics indicate that the landscape within the urban fringe transformed from fragmentation to regularization, and the development of the urban fringe transformed from a disorderly to an orderly manner. This condition is mainly due to the reduction of available land because the area of urban construction land was controlled by the master plan of the city.

The present work hopes to provide basic support for the study of urban fringe social and environmental problems and urban planning. The reasons for the changes in urban fringes differ, and the problems in urban fringe are complex. This study is insufficient for the quantitative analysis of factors affecting urban fringe changes. With historical and fine-scale social and economic data, the reasons and effects of urban fringes are worth studying in the future. Moreover, through the prediction of future urban land use change, evaluating the future changes of urban fringe areas is also meaningful.

Author Contributions: S.C. and Q.J. designed the paper. S.C. and Z.W. analyzed the data and wrote the paper. S.X. and M.J. provided suggestions to improve the study and the manuscript. All authors have read and approved the final manuscript.

Funding: This study is supported by the Chinese National Science Foundation (No. 41371332) and a project funded by the China Geological Survey (DD20160077).

Acknowledgments: The authors would like to thank the anonymous reviewers and handling editors for their constructive comments.

Conflicts of Interest: The authors declare no conflict of interest.

\section{References}

1. Louis, H. Die geographische Gliederung von Gross-Berlin; Stuttgart Engelhorn: Berlin, Germany, 1936.

2. Yang, Y.; Ma, M.; Tan, C.; Li, W. Spatial Recognition of the Urban-Rural Fringe of Beijing Using DMSP/OLS Nighttime Light Data. Remote Sens. 2017, 9, 1141. [CrossRef]

3. Wang, S.; Li, S.; Liu, J. Discussion on land use regulation in urban-rural fringe zone. J. Geomat. 2000, 4, 15-19.

4. Li, J.; Qiu, R.; Li, K.; Xu, W. Informal Land Development on the Urban Fringe. Sustainability 2018, 10, 128. [CrossRef]

5. Gu, C.; Hu, L.; Ian, G. China's Urbanization in 1949-2015: Processes and Driving Forces. Chin. Geogr. Sci. 2017, 27, 847-859. [CrossRef]

6. Newton, P.; Meyer, D.; Glackin, S. Becoming Urban: Exploring the Transformative Capacity for a Suburban-toUrban Transition in Australia's Low-Density Cities. Sustainability 2017, 9, 1718. [CrossRef]

7. Huang, J.; Zhou, Q.; Wu, Z. Delineating Urban Fringe Area by Land Cover Information Entropy—An Empirical Study of Guangzhou-Foshan Metropolitan Area, China. ISPRS Int. J. Geo-Inf. 2016, 5, 59. [CrossRef]

8. Fu, C.; Chen, M. Research progress of urban and rural fringe in China. Prog. Geogr. 2010, 29, 1525-1531.

9. Ma, Z.; Li, L.; Yan, Y.; An, D. Analysis of city spatial expansion characteristics and influencing factors of transitional zone city: taking Zhangjiakou city as an example. J. Tianjin Norm. Univ. Nat. Sci. Ed. 2014, 3, $56-61$. 
10. Xun, W.; Wang, Y.; Jia, Y. Spatial identification and the evolvement of land use structure of rural-urban rapidly urbanized area-A case study of Shenyang. Terr. Nat. Resour. Study 2015, 5, 12-15.

11. Xu, G.; Chen, B.; Yao, M. Research on the division methods of spatial boundary in urban-rural fringe. J. Anhui Agric. Sci. 2010, 38, 995-998.

12. Zhang, W.; Fang, X.; Zhang, L. Method to identify the urban-rural fringe by TM images. J. Remote Sens. 1999, 3, 210-220.

13. Lesage, J.; Charles, J. Using home buyers revealed preferences to define the urban-rural fringe. J. Geogr. Syst. 2008, 10, 1-21. [CrossRef]

14. Wadduwage, S.; Millington, A.; Crossman, N.D.; Sandhu, H. Agricultural Land Fragmentation at Urban Fringes: An Application of Urban-To-Rural Gradient Analysis in Adelaide. Land 2017, 6, 28. [CrossRef]

15. Wang, Y.; Jiang, B.; Chu, N.; Dai, L.; Li, X.; Ma, Y.; Zhang, X. Extraction method and expansion patterns of the urban fringe based on construction land change: A case in Harbin city. Econ. Geogr. 2016, 5, $26-32$.

16. Zhang, N.; Fang, L.; Zhou, J.; Song, J.; Jiang, J. The study on spatial expansion and its driving forces in the urban fringe of Beijing. Geogr. Res. 2010, 3, 471-480.

17. Converse, P. New laws of retail gravitation. J. Mark. 1949, 14, 379-384. [CrossRef]

18. Yang, Y.; Wang, Y.; Wu, K.; Yu, X. Classification of Complex Urban Fringe Land Cover Using Evidential Reasoning Based on Fuzzy Rough Set: A Case Study of Wuhan City. Remote Sens. 2016, 8, 304. [CrossRef]

19. Schneider, A. Monitoring land cover change in urban and peri-urban areas using dense time stacks of Landsat satellite data and a data mining approach. Remote Sens. Environ. 2012, 124, 689-704. [CrossRef]

20. Riitters, K.H.; O’Neill, V.; Hunsaker, C.T.; Wickham, J.D.; Yankee, D.H.; Timmins, S.P.; Jones, B.K.; Jackson, B.L. A factor analysis of landscape pattern and structure metrics. Landsc. Ecol. 1995, 10, 23-39. [CrossRef]

21. Yang, J.; Guan, Y.; Li, X.; Xi, J. Urban fringe area ecological vulnerability space-time evolution research: The case of Ganjingzi District, Dalian. Acta Ecol. Sin. 2018, 38, 778-787. [CrossRef]

22. Theohald, D.M. Land use dynamics beyond the urban fringe. Geogr. Rev. 2001, 91, 544-564. [CrossRef]

23. Ma, S.; Chen, W.; Zhang, S.; Tong, Q.; Bao, Q.; Gao, Z. Characteristics and cause analysis of heavy haze in Changchun City in Northeast China. Chinese Geogr. Sci. 2017, 6, 989-1002. [CrossRef]

24. Lu, D.S.; Li, G.Y.; Kuang, W.H.; Moran, E. Methods to extract impervious surface areas from satellite images. Int. J. Digit. Earth 2014, 7, 93-112. [CrossRef]

25. Yu, W.J.; Zhou, W.Q.; Qian, Y.G.; Yan, J.L. A new approach for land cover classification and change analysis: Integrating backdating and an object-based method. Remote Sens. Environ. 2016, 177, 37-47. [CrossRef]

26. $\mathrm{Xu}, \mathrm{W}$. The Changing Dynamics of Land use Change in Rural China: A Case Study of Yuhang, Zhejiang Province. Environ. Plan. 2004, 36, 1595-1615. [CrossRef]

27. Yu, D.; Wang, D.; Li, W.; Liu, S.; Zhu, Y.; Wu, W.; Zhou, Y. Decreased Landscape Ecological Security of Peri-Urban Cultivated Land Following Rapid Urbanization: An Impediment to Sustainable Agriculture. Sustainability 2018, 10, 394. [CrossRef]

28. Graves, R. Ecotone. Available online: http:/ / www.eoearth.org/view/article/152345 (accessed on 15 February 2016).

29. Bhatta, B. Analysis of urban growth pattern using remote sensing and GIS: A case study of Kolkata, India. Int. J. Remote Sens. 2009, 30, 4733-4746. [CrossRef]

30. Cheng, L.; Zhao, H. Discussion on the city's border area of Beijing. J. Beijing Norm. Univ. Nat. Sci. 1995, 31, 127-133.

31. Bian, Z.; Wang, X. Urban fringes extension by using GIS and RS in Shenyang. J. Shenyang Agric. Univ. 2015, 46, 316-321.

32. Qian, Z.; Chen, X. The research on division methods of urban fringe-A case study of Xi'an. J. Grad. Sun Yat-Sen Univ. 2006, 26, 54-62.

33. Qian, J.; Zhou, Y.; Yang, X. Confirmation of urban fringe area based on remote sensing and message entropy: A case study of Jingzhou, Hubei Province. Resour. Environ. Yangtze Basin. 2007, 16, 451-455.

34. McGarigal, K.; Marks, B. Fragstats-Spatial Pattern Analysis Program for Quantifying Landscape Structure; Forest Science Department, Oregon State University: Corvallis, OR, USA, 1994.

35. Li, X.; Li, H.; Zhang, Y.; Yang, L. Spatial Patterns and the Regional Differences of Rural Settlements in Jilin Province, China. Sustainability 2017, 9, 2170. [CrossRef]

36. Ripley, B.D. The second-order analysis of stationary point processes. J. Appl. Probab. 1976, 13, $255-266$. [CrossRef] 
37. Wu, J.; Shen, W.; Sun, W.; Tueller, T.P. Empirical patterns of the effects of changing scale on landscape metrics. Landsc. Ecol. 2002, 17, 761-782. [CrossRef]

38. Chen, L.; Ren, C.; Zhang, B.; Wang, Z.; Liu, M. Quantifying Urban Land Sprawl and its Driving Forces in Northeast China from 1990 to 2015. Sustainability 2018, 10, 188. [CrossRef] 